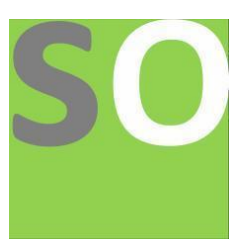

Article title: COVID-19 and SARS-COV-2 Infection and Virulence, Hypothesis II: Elevated Temperature, Humidity and Far Infrared Irradiation will significantly lower the Viability, Infectivity and Virulence of SARS-COV-2

Authors: H.Y. Lim Tung[1]

Affiliations: Nachbraht Biomedical Research Institute[1]

Orcid ids: 0000-0002-7112-7477[1]

Contact e-mail: hyltung2010@nacbrahtbiomedresins.net

License information: This work has been published open access under Creative Commons Attribution License http://creativecommons.org/licenses/by/4.0/, which permits unrestricted use, distribution, and reproduction in any medium, provided the original work is properly cited. Conditions, terms of use and publishing policy can be found at https://www.scienceopen.com/.

Preprint statement: This article is a preprint and has not been peer-reviewed, under consideration and submitted to ScienceOpen Preprints for open peer review.

DOI: 10.14293/S2199-1006.1.SOR-.PP4VZ1S.v1

Preprint first posted online: 20 April 2020

Keywords: COVID-19, SARS-COV-2, Viability, Infectivity and Virulence, High Humidity, High Temperature, Far Infrared Irradiation, Inflammation, Nitrous Oxide, NFkB, Inhibitor of NFkB 


\title{
COVID-19 AND SARS-COV-2 INFECTION AND VIRULENCE, HYPOTHESIS II: ELEVATED TEMPERATURE, HUMIDITY AND FAR INFRARED IRRADIATION WILL SIGNIFICANTLY LOWER THE VIABILITY, INFECTIVITY AND VIRULENCE OF SARS- COV-2, A RELATIVELY EASY HYPOTHESIS THAT CAN BE TESTED IN LESS THAN TWO WEEKS
}

\author{
H.Y. Lim Tung
}

Peptide and Protein Chemistry Research Laboratory, Nacbraht Biomedical Research Institute, 3164 21st Street, Suite 117, Astoria (NYC), New York 11106, USA.

Correspondence to:

H.Y. Lim Tung

Peptide and protein Chemistry Research Laboratory

Nachbraht Biomedical Research Institute

3164 21st Street, Suite 122

Astoria (NYC), NY 11106

USA

Tel: 332-201-7161

Fax: 332-777-2655

E mail: hyltung2010@nacbrahtbiomedresins.net 


\begin{abstract}
.
SARS-COV-2 is the etiologic agent of COVID-19. There is currently no effective means of preventing infections by SARS-COV-2, except through restriction of population movement and contact. An understanding of the origin, evolution and biochemistry (molecular biology) of SARS-COV-2 is a prerequisite to its control. There is no definitive answer as to the origin of SARS-COV-2. The evolution of SARS-COV-2 can be gleaned from a comparative study of its infectivity and virulence in different populations and environments. There are few reports on the biochemistry (molecular biology) of SARS-COV-2. Analysis of the biochemistry (moleuclar biology) of SARSCOV-2 and past discoveries of viruses that infect humans revealed that SARS-COV-2 most probably emerged from its latent forms through induction by Low Temperature, Low Sunlight and Low Humidity caused by Seasonal Change and Drought. Far Infrared Radiation (FIR), an important component of Sun Light can eradicate RNA viruses. Thus, it is hypothesized that an environment of high humidity, temperature approaching $39^{\circ} \mathrm{C}$ (or higher) and Far Infrared Irradiation will significantly lower the viability and infectivity of SARS-COV-2 and enhance the recovery of individuals infected with SARS-COV-2. Increasing the temperature and humidity with constant Far Infrared Irradiation in the room in which individuals infected with SARS-COV-2 are being treated is relatively easy to implement. Protocol for irradiation with FIR which is not harmful to humans but will destroy SARS-COV-2 already exists and can be implemented relatively easy. It is also hypothesized that the process of steaming up to $70^{\circ} \mathrm{C}-80^{\circ} \mathrm{C}$ in a FIR Sauna may not only reduce the viability and infectivity of SARS-COV-2 but also enhance the recovery of individuals infected with SARS-COV-2. It is further hypothesized that Individuals infected with SARS-COV-2 who have mild symptoms and Asymptomatic Carriers of SARS-COV-2 will also benefit from steaming in a FIR Sauna. These hypotheses are realtively easy to test and will take no more than two weeks to accomplish.
\end{abstract}


SARS-COV-2 is the etiologic agent of COVID-19 which is now considered a Pandemic [1-3]. Currently, while various prophylactics and oxygenation have helped the recovery from severe illnesses, the only effective means of avoiding morbidity due to infections by SARS-COV-2 is through population control and contact restriction which appear to be quite effective in some parts of the world and not others [4,5]. The DP10000 Number or Number of Deaths Per 10000 Individuals Infected with SARS-COV-2 in various populations and regions of the world are not uniform [5]. Although the Medical Infrastructure and Response Strategy and Protocol play an important role in mitigating illnesses and deaths as a result of SARS-COV-2 infections, the possibility that variability in the DP10000 Numbers for SARS-COV-2 in various populations and regions of the world may be due to SARS-COV-2 mutations cannot be ruled out [5]. There is some evidence showing that the biochemistry (molecular biology) of SARS-COV-2 sub-strains may be different in various populations and regions of the world [5-7].

It was Lwoff and co-workers who first coined the termed "Prophage" to describe an entity which was not yet a full-fledged "Bacteriophage" which is the equivalent of a Virus in Bacteria [8]. Lwoff and co-workers realized that a "Prophage" could be induced by irradiating the host Bacteria with Ultraviolet Radiation and concluded that Ultraviolet Radiation was the agent that induced or unleash the pathogenicity of the "Bacteriophage" (the equivalent of Virus in mammals including humans). that was dormant but always there in the form of a "Prophage" [9]. The importance of Virus Induction was recognized and generalized in Viruses that infect mammalian cells, including humans [10,11]. Lwoff [11] used the example of Herpes Simplex Virus to illustrate Viral Induction in humans. Herpes Simplex Virus is associated with what is termed Latent Infection which does not cause any disease and which does not produce Infectious Viruses. The fact that no Viruses can be detected does not mean that there are no Viruses. The Viruses could be present at very low levels or in a latent form just like in the case of the Bacterial Virus, the "Bacteriophage". There are many Agents of Viral Induction, including Temperature, pH, Humidity, Viscosity and UV Radiation [10,11]. High temperature is also a negative controller of Viral Development and Replication. Quoting the work of Thompson and Coates [12] who showed the effect of temperature on viral development, Lwoff [10] 
lamented that "The temperature problem did not succeed in capturing the attention of scientists, as exemplified by the fact that the subject is hardly mentioned or not mentioned at all in textbooks or treatises of animal virology. Why this work did not develop is a mystery. A scientist must not only have the right idea, do the right experiments, and give birth to a paper. He also must build a coherent doctrinal corpus and must force it into reviews and textbooks (And must force it also into the brains of his colleagues.)". Subsequent studies by Armstrong [13] showed that that mice infected with Herpes Simplex Virus died at room temperature and not at higher temperature. Lwoff and Lwoff [14] and Lwoff et al [15] described the effects of hyperthemia on Polio Virus Virulence and showed that 10/25 mice infected with Polio Virus Type II survived when they were kept at $36.5^{\circ} \mathrm{C}$ whereas none surviced when they were kept at $20^{\circ} \mathrm{C}$ (which is room temeprature), and proposed that "hyperpyrexia may save an animal infected intracerebrally by a high dose of a virulent strain of poliovirus, or transform a hyperacute disease into a latent infection".

Morikawa et al. [16] reported that they could identify several viruses associated with Respiratory Tract Diseases in asymptomatic individuals, including human parechovirus, adenovirus, enterovirus, rhinovirus, coronavirus 229E and HKU1, suggesting Virus Dormancy or Latency. Allen et al [17] observed that an outbreak of common colds occured in an isolated station in Antartica after a sudden change in weather that brought the temperature down from a high of $1-2^{0} \mathrm{C}$ to a low of $-24^{0} \mathrm{C}$ and reduced the relative outside humidity from $93 \%$ to $79 \%$ and postulated that the sharp decrease of temperature may explain "the persistence of large number of rhinovirus serotypes". Muchmore et al. [18] related that Parainfluenza virus types 1 and 3 could be recovered from both asymptomatic and symptomatic subjects throughout winter in an isolated station in the South Pole and concluded that the viruses could not have been introduced and were most probably due to "persistence in man". Shaw-Stewart [19] proposed that the "natural temprrature sensitivity of respiratory viruses" allows virions to become dormant and viral activation as a result of chilling. 
There is a debate concerning the origin of SARS-COV and SARS-COV-2. Until there is definitive proof that SARS-COV and SARS-COV-2 came from animals including bats and other mammals as intermediate carriers [1-3], the possibility that SARS-COV and SARS-COV-2 were dormant or latent viruses that became induced by specific agents including low temperature and low humidity cannot be ruled out. In the case of SARSCOV and SARS-COV-2, agents of Viral Induction include Temperature, $\mathrm{pH}$, Viscosity, Low Humidity and UV Radiation. It is generally accepted that both SARS-COV and SARS-COV-2 emerged during the winter months which provides an ideal environmental condition for the viability and infectivity of SARS-COV and SARS-COV-2 and that low humidity significantly contributed to the emergence of both SARS-COV and SARSCOV-2 [20]. Low sunlight is also accompanied by low level of Far Infrared Radiation (FIR) because approximately $49 \%$ of the sun's energy that reaches earth is in the form of Infrared Radiation.. Chan et al. [21] showed that at a temperature of $\sim 38^{\circ} \mathrm{C}$ and relative humidity greater than $95 \%$, there was a significant loss of SARS-COV viability and infectivity than at $\sim 33^{\circ} \mathrm{C}$ and relative humidity greater than $95 \%$ indicating that SARSCOV preferred a low temperature and low humidity for its viability and infectivity. Sun et al. [20] have reported that both SARS-COV and SARS-COV-2 emerged during winter in 2002 and 2020 respectively after a drought season around Foshun, China and Wuhan, China. Yamaya et al. [22] showed that another Virus, H1N1 which was responsible for the 2009 Pandemic also emerged during winter and were susceptible to temperatures nearing $40^{\circ} \mathrm{C}$. Specifically, Yamaya et al. [22] showed that at 120 hours post-infection, six different strains of H1N1 exhibited lower titers (i.e infectivity) in cells cultured at $40^{\circ}$ $\mathrm{C}$ than in cells cultured at $37^{\circ} \mathrm{C}$. Yamaya et al. [22] also reported that levels of inflammatory cytokines (the agents that negatively affect individuals infected with various viruses) in cells infected with $\mathrm{H} 1 \mathrm{~N} 1$ were lower at $40^{\circ} \mathrm{C}$ than at $37^{\circ} \mathrm{C}$. Yamaya et al. [22] concluded that exposure to temperature above $39^{\circ} \mathrm{C}$ may reduce the replication of pandemic and seasonal Influenza Virus. However, inexplicably, they did not propose that treatment of infected individuals should include induction of sweating which would not only act to significantly reduce fever but also reduce the viability and infectivity of H1N1. 
It is a common laboratory procedure to use Ultra Violet Radiation (UVR) to destroy microorganisms and other biological entities, including viruses [23,24]. However, UVR is generally harmful to humans as it has been shown to cause cell damage [25]. The use of photochemically generated reactive oxygen species (ROS), including singlet oxygen for the inactivation of viruses are also very effective [27-29]. However, the common use of Chemotherapy based anti-virals supplanted the use of either UVR or Photodynamic Therapies. Recent advances in the inactivation of viruses via Photodynamic means and the fact that there is curently no effective anti-virals or vaccines against SARS-COV-2 indicate that Photodynamic Therapies merit further exploration. On the other hand, the effectiveness of Far Infrared Radiation (FIR) in destroying microorganisms and other biological entities, including SARS-COV-2 is proven [30]. FIR Therapy has also been shown to reduce inflammatory response due to viral infection by enhancing the production of nitrous oxide which is one of the mechanisms to inhibit NFkB, an important regulator of inflammatory response [31,32]. Protocols in various forms exist already to treat humans and can be applied to combat SARS-COV-2 immediately [30,33].

Based on the above findings, it is submitted and hypothesized that an environment of high humidity and temperature approaching $39^{\circ} \mathrm{C}$ (or more if it is not too uncomfortable) and constant FIR irradiation will significantly lower the viability and infectivity of SARS-COV-2 and significantly enhance the recovery of individuals infected with SARS$\mathrm{COV}-2$. It is also hypothesized that the process of steaming up to $70^{\circ} \mathrm{C}-80^{\circ} \mathrm{C}$ in a FIR Sauna may not only reduce the viability and infectivity of SARS-COV-2 but also enhance the recovery of individuals infected with SARS-COV-2. It is further hypothesized that Asymptomatic Carriers of SARS-COV-2 will also benefit as the above will reduce the infection of the population by Asymptomatic Carriers of SARS-COV-2. It must be noted that (i) the above hypotheses have not been scientifically validated, (ii) remain untested hypotheses, and (ii) this report does not constitute a prescription. However, it is consistent with the findings of Lwoff and Lwoff [14] and Lwoff et al [15].

The hypothesis that an environment of high humidity and temperature approaching $39^{\circ} \mathrm{C}$ and FIR irradiation will significantly lower the viability and infectivity of SARS-COV-2 
and significantly enhance the recovery of individuals infected with SARS-COV-2, and that the process of steaming up to $70^{\circ} \mathrm{C}-80{ }^{\circ} \mathrm{C}$ in a FIR Sauna may not only reduce the viability and infectivity of SARS-COV-2 but also enhance the recovery of individuals infected with SARS-COV-2. is based on common sense and is supported by the findings Lwoff and co-workers [8,11], Chan et al. [12], Yamaya et al. [14], and Tung [5, Tung, H.Y.L. Manuscript in preparation]. The use of Far Infrared Radiation Therapy is not unlike Radiotherapy first discovered by Marie Curie. Protocol for the requirements of the above hypotheses exist already and can be implemented immediately.

\section{References.}

1. Zhu, N., Zhang, D., Wang, W., Li, X., Yang, B., Song, J., Zhao, X., Huang, B., Shi, W., Lu, R., Niu, P., Zhan, F., Ma, X., Wang, D., Xu, W., Wu, G., Gao, G.F. and Tan, W. (2019) N. Engl. J. Med., Vol. 382, pp727-733.

A novel coronavirus from patients with pneumonia in China, 2019.

2. Lu, R., Zhao, X., Li, J., Niu, P., Yang, B., Wu, H., Wang, W., Song, H., Huang, B., Zhu, N., Bi, Y., Ma, X., Zhan, F., Wang, L., Hu, T., Zhou, H., Hu, Z., Zhou, W., Zhao, L., Chen, J., Meng, Y., Wang, J., Lin, Y., Yuan, J., Xie, Z., Ma, J., Liu, W.J., Wang, D., Xu, W., Holmes, E.C., Gao, G.F., Wu, G., Chen, W., Shi, W. and Tan, W. (2020) Lancet, Vol. 395, pp565-574.

Genomic characterisation and epidemiology of 2019 novel coronavirus: implications for virus origins and receptor binding.

3. Zhou, P., Yang, X.L., Wang, X.G., Hu, B., Zhang, L., Zhang, W., Si, H.R., Zhu, Y., Li, B., Huang, C.L., Chen, H.D., Chen, J., Luo, Y., Guo, H., Jiang, R.D., Liu, M.Q., Zhao, K., Chen, Q.J., Deng, F., Liu, L.L., Yan, B., Zhan, Q.J., Deng, F., Liu, L.L., Yan, B., Zhan, F.X., Wang, Y.Y., Gao, G.F. and Shi, Z.L. (2020) Nature, Vol. 579, pp270-273.

A pneumonia outbreak associated with a new coronavirus of probable bat origin.

4. Wu, F., Zhao, S., Yu, B., Chen, Y.-M., Wang, W., Song, Z.-G, Hu, Y., Tao, Z.W., Tian, J.-H., Pei, Y.-Y., Yuan, M.-L., Zhang, Y.-L., Dai, F.-H., Liu, Y., Wang, Q.-M., Zheng, J.-J., Xu, L., Holmes, E.C. and Zhang, Y.Z. (2020) Nature, Vol., 579, pp265-269. 
A new coronavirus associated with human respiratory disease in China.

5. Tung, H.Y.L. (2020) ScienceOpen, DOI: 10.14293/S2199-1006.1.SOR.PPXVKPX.v1

COVID-19 and SARS-COV-2 Infection and Virulence: Hypothesis I.

6. Tang, X., Wu, C., Li, X., Song, Y., Yao, X., Wu, X., Duan, Y., Zhang, H., Wang, Y., Qian, Z., Gui, J. and lu, J. (2020) National Science Review, https:// doi.or/ 10.1093/nsr/nmaa0036/5775463.

On the origin and continuing evolution of SARS-CoV-2.

7. Ou, J., Zhou, Z., Zhang, J., Lan, W., Zhao, Wu, J., Seto, D., Zhang, G. and Zhang, Q. (2020) bioRxiv, https://doi.org/10.1101/2020.03.15.991844.

RBD mutations from circulating SARS-CoV-2 strains enhance the structure stability and infectivity of the spike proteins.

8. Lwoff, A. (1966) Science, Vol. 152, pp1216-1220.

Interaction among virus, cell and organism.

9. Lwoff, A. (1953) Bacteriol Rev. 1953;17(4):269-337.

Lysogeny.

10. Lwoff, A. (1959) Bacteriol. Rev. Vol. 23, 109-124.

Factors influencing the evolution of viral diseases at the cellular level and in the organism. Bacteriological reviews, 23(3), 109-124.

11. Lwoff, A. (1965) Biochem. J., Vol. 96, pp289-301].

The specific effectors of viral development.

12. Thompson, R.L. and Coates, M.S. (1942) J. Infectious Diseases, Vol. 71, 83-85. The effect of temperature upon the growth and survival of myxoma, herpes and vaccinia viruses in tissue culture.

13. Armstrong, C. (1942) Military Surgeon, Vol. 91, pp129-145.

Some recent research in the field of neurotropic viruses with especial reference to lymphocytic choriomeningitis and herpese simplex.

14. Lwoff, A. and Lwoff, M. (1958) Compt. Rend., Vol. 246, pp190-192.

L' Inhbition du development du virus poliomyelitique a 390 et le probleme du role de l'hyperthermie dans l' evolution des infections virales. 
15. Lwoff, A., Tournier, P. and Cartaud, J.P. (1959) Compt. Rend., Vol. 248, pp18761878.

Influence de l' hyperthermie experimentale sur la poliomyelite de la souris.

16. Morikawa, S., Hiroi, S., \& Kase, T. (2015) J. Clin. Virol., Vol. 64, pp59-63. Detection of respiratory viruses in gargle specimens of healthy children.

17. Allen, T. R., Bradburne, A. F., Stott, E. J., Goodwin, C. S., \& Tyrrell, D. A. (1973) J. Hygiene, Vol 71, pp657-667.

An outbreak of common colds at an Antarctic base after seventeen weeks of complete isolation.

18. Muchmore, H.G., Parkinson, A.J., Humphries, J.E., (1981) Nature, Vol. 289, pp187-189.

Persistent parainfluenza virus shedding during isolation at the South Pole.

19. Shaw-Stewart P. D. (2016). Medical Hypotheses, Vol. 86, pp104-119.

Seasonality and selective trends in viral acute respiratory tract infections.

20. Sun, (2020) Int. J. Environ. Res. Public Health, Vol. 17, DOI:

10.3390/ijerph17051633.

Potential factors influencing repeated SARS outbreaks in China.

21. Chan, (2011) Advances in Virology, DOI: 10.11155/2011/734690, The effects of temperature and relative humidity on the viability of SARS Coronavirus.

22. Yamaya, (2019) [Heliyon, Vol. 5, DOI: 10.1016/j.heliyon2019.e01149. Effects of high temperature on pandemic and seasonal human influenza viral replication and infection-induced damage in primary human tracheal epithelial cell cultures.

23. Cutler, T.D. and Zimmerman, J.J. (2011) Anim. Health Res. Rev., Vol. 12, pp15-23.

Ultraviolet irradiation and the mechanisms underlying its inactivation of infectious agents.

24. McDevitt, J.J., Milton, D.K., Rudnick, S.N. and First, M.W. (2008) PloS One, Doi:10.1371/journal.pone.0003186. 
Inactivation of poxviruses by upper-room UVC light in a simulated hospital room environment.

25. Cleaver, J.E., and Crowley, E. (2002) Front Biosci., Vol. 7, pp1024-1043.

UV damage, DNA repair and skin carcinogenesis.

27. Muller-Breitkreutz, K., Mohr, H., Brivida, K. and Sies, H. (1995) J.Photochem.

Photobiol. B., Vol. 30, pp63-70.

Inactivation of viruses by chemically and photochemically generated singlet

molecular oxygen.

28. Wainwright,M. (2003) Int. J. Antimicrob. Agents., Vol. 21, pp510-520.

Local treatment of viral disease using photodynamic therapy.

29. Hamblin, M.R. (2016) Curr. Op. Microbiol., Vol. 33, pp67-73.

\section{Antimicrobial photodynamic inactivation: a bright new technique to kill}

\section{resistant microbes.}

30. Li, E.-J and Huang, W.-H. (2020) Preprints,

Doi:10.20944/preprints202002.0332.v1).

Instability of nucleic acids in airborne microorganisms under far infrared radiation.

31. Leung, T.-K., Lin, Y.-S., Chen, Y.-C., Shang, H.-F., Lee, Y.-H., Su, C.-H., Liao, H.-C. and Chang, T.-M. ( 2009) Biomedical Engineering: Applications, Basis and Communications, Vol. 21, pp. 317-323

Immunomodulatory effects of far-infrared ray irradiation via increasing calmodulin and nitric oxide production in raw 264.7 macrophages.

32. Matthews, J. R., Botting, C. H., Panico, M., Morris, H. R., and Hay, R. T. (1996). Nucleic Acids Res., Vol. 24, pp2236-2242.

Inhibition of NF-kappaB DNA binding by nitric oxide.

33. Vatansever, F. and Hamblin, M.R. (2012) Vol. 4, 255-266.

Far infrared radiation (FIR): its biological effects and medical applications. 